Article

\title{
Communication Barriers and Lessons Learned in Energy Policy
}

\author{
Hollie Smith ${ }^{1,2, *(1)}$ and Christine Gilbert ${ }^{2}$ \\ 1 Department of Marine Affairs, University of Rhode Island, Kingston, RI 02881, USA \\ 2 Harrington School of Communication and Media, University of Rhode Island, Kingston, RI 02881, USA; \\ cmgilbert@my.uri.edu \\ * Correspondence: holliesmith@uri.edu; Tel.: +1-401-874-2110
}

Received: 29 December 2017; Accepted: 6 February 2018; Published: 9 February 2018

\begin{abstract}
In the past 30 years, energy researchers have concluded their academic publication with sections that deal directly with policy implications and recommendations. Yet too often, these recommendations are written with little understanding of how policymakers balance different needs, prefer to communicate, or use scientific information. In this manuscript, we outline key variables-time, training, and interpretation-that are key to understanding how to better communicate research implications to policymakers. We recommend emphasizing the power of language and the use of boundary objects in an attempt to mitigate the issues presented between researchers and policymakers.
\end{abstract}

Keywords: energy policy; science communication; deficit model; communication theory

\section{Introduction}

Policy implications and recommendations have become a standard concluding component of energy studies and reports. These recommendations are written in an effort to inform the decisions made by policymakers and aid in the creation of a viable and sustainable energy policy network for years to come. Yet too often, these recommendations are written without consideration of the unique context in which policymaking happens-one that is defined by human influence, partisan politics, and a demand on decision makers to balance competing economic, social, or environmental needs. To more realistically move energy research into policy practice, we must take a nuanced view of both the policymaking process and the role these recommendations play in context to other demands and timelines.

Energy research most frequently focuses on the technical and economic dimensions of energy production and consumption [1-3]. While these areas are of utmost importance for understanding energy systems, there is often a lack of the human dimensions that influences key decisions around the technology being studied [2]. In an extensive review of current energy research, Sovacool [2] found that only 0.3 percent of articles published in leading energy journals from 1999-2013 came from authors affiliated with social science departments such as history, communication, or sociology. The integration of these social perspectives along with the natural sciences is crucial to extending scientific reach from academia to policy. As Stern, Sovacool, and Dietz [4] note, "social forces-such as power, culture, and institutional arrangements-shape the scale, content, techniques and trajectories of production, distribution, and the use of goods and services and their associated uses of energy." (p. 548). In particular, communication processes are often overlooked or oversimplified in the context of energy policy recommendations. The placement of energy policy recommendations at the end of research articles models the deficit approach to communication, with the belief that if people-policymakers in this instance-have sound scientific evidence they will use it. A large body of literature has shown that the deficit model is inadequate in most cases and science communication researchers have largely 
encouraged a move toward a dialogue-centric approach, where conversation happens in a two-way flow of information among scientists and other groups [5-7]. In this manuscript, we review two models of communication that inform the theoretical framework for thinking about science and policy communication. Then we outline key themes - time, training, and interpretation - that often define science/policy interactions and offer things to consider when communicating within energy research contexts.

\section{The Science Policy Nexus and the Deficit Model of Communication}

There are clear divides between the world of energy researchers and policy makers when it comes to priorities, demands, and timelines. Researchers often study one technology or energy system, focusing in on the potential of that technology in a controlled or static environment. Policymakers, in contrast, have to make decisions that consider technical and social dynamics, including the current and future political climate, constituency demands, and economic consequences. Scientists have historically approached bridging the gap between science and policy with a one-way model of communication, assuming that if they communicated research results, policymakers, communities, or the public would use the information upon successful transmission. This "deficit model" approach to science communication has been largely unsuccessful and often criticized for being too $[5,6]$ with a lack of understanding of why certain individuals or groups do not use scientific information [7]. The general purpose for science communication practice, as Suldovsky [5] notes, "is to improve the relationship between science and society and promote science within the public sphere through a variety of means, including improving scientific literacy, connecting science and policy, cultivating positive perceptions of science, or disseminating scientific information to the public" (p. 417). In response to the lack of success with the deficit model, scholars and practitioners have been moving toward a two-way, dialogic approach to communication, while still recognizing the complications that come with this shift [5]. Smith, Suldovsky, and Lindenfeld [8] outlined the difficulties that scientists who directly engage with policymakers can face, including role strain and disincentives from the scientific community. While the communication between scientists and policymakers is an inherently complex endeavor, we argue that adopting a dialogic approach in energy research is important for making policy recommendations more usable.

The dialogic approach to communication requires that communicators understand who is involved in the communication act and what influences the context of the situation. Thinking about how research impacts decision-making at a system level brings to light the various types of boundaries scientists and decision-makers must cross when trying to align their information, goals and processes. This notion of boundary crossing through communication highlights the differences in priorities, values, and group norms within the science and policy realms [9]. To better understand how to bridge the gap between science and policy, we need to understand what barriers exist at individual and institutional levels, what strategies have been used to overcome them, and what are the new opportunities for successful communication?

\section{Themes Identified: Key Barriers between Science and Policy}

\subsection{Timelines}

One of the key barriers to effective communication between research and policy is a continual mismatch in the timing of decision makers' needs for information and the availability of research results [10]. It is clear that decision-support information can only be useful if it is accessible in a timely manner to those who need it [11]. For decision makers, the need for information does not follow a linear or often times rational sequence, as they have a need to respond flexibly to changing political climates [12]. Decision makers are accountable to agencies, publics, and stakeholders, and often need to make a decision when "windows of opportunities" for change occur-that is when problem recognition and pressures for political responses happen simultaneously [12] (p. 49). 
Many factors can create or influence the timing of these windows of opportunity, including the actions of prominent individuals who have specialized interests, agenda-setting activities, coalition building and the presence of feasible policy options [13]. Anticipating these policy windows encompasses the need for thinking about what will be the emerging and future issues of our time, and understanding what events that might trigger these opportunities. An example of recent trigger events includes the intensifying effects of recent hurricanes in the North Atlantic. With each big storm, there opens up a window of opportunity for discussion about how climate change is related to storm intensity, the models for future storms, and how to ready coastal communities for the predicted impacts [14]. Being prepared for these opportunities takes significant time in itself, and requires relationship building and established communication channels so when these opportunities arise, the information is ready. And even then, studies have suggested that there exists a lagging pattern between media coverage of trigger events and legislation being introduced at the state level [15]. Preparation and ability to relay information quickly is important as these windows of opportunities close when there is pressure to get back to business as usual [11].

The politics embodied in the need for science [16] only account for half of the mismatch, with academia's timeline being equally as problematic. Scientists are accountable to funding agencies, academic institutions, and disciplinary roots [11]. Researchers working within the academy are subject to the process of peer-review, which on average takes more than three months [17-19] and "substantially slows the transmission of ideas beyond academic institutions" [18] (p. 317). The timeline is extended even more if the way the research is written has to be reworked to focus more toward a decision-making audience rather than an academic journal [18]. These distinctive timelines and levels of accountability are one contributing factor to the misalignment in the supply and demand for scientific knowledge.

\subsection{Purpose and Scale of Research}

Another reason noted for the systematic divide between policy and research is the "excessive professional and organizational distance" between the two arenas [10] (p. 768). Researchers and policymakers often interact only sporadically, which doesn't allow time to build trust or an understanding of what decision makers need to know and what is realistic for science to provide [11,15]. The question addressed in this section is fundamentally about the purpose of research. Throughout the policy studies literature we can see an expressed need for research specifically conducted to inform policy $[11,16,20]$. This is important as it marks a difference from traditional research, which is necessary, but only secondarily transpires to be policy relevant [20] (p. 16). Two examples can highlight the importance of clarifying the purpose of research. Ahmed [10] details a case of several international development agencies shifting aid allocation criteria because of research done to inform the transition. His conclusion was that while other factors were at play, the most critical factor for this research-policy success was researchers "made it clear that their objective was not simply to add to the stock of human knowledge," but it was to make more efficient the way aid was allocated in actual practice (p. 767). To highlight the other end of the spectrum, Sarewitz and Pielke [16] note a missed opportunity for alignment and influence in climate change science. There is much agreement within the scientific community about climate change, yet much of the climate science has yet to change decision-making, in part because the necessary feedback between the demand and production of science largely has not taken place. Sarewitz and Pielke [16] attribute part of climate science's failure to inform decision-making processes to the fact that "the question of whether what we presently know is what we need to know to act effectively was not addressed" (p. 11). These examples and a review of the literature highlight the need for certain research endeavors to be policy-focused and action-oriented, with researchers paying specific attention to the questions of "what we need to know to act effectively".

Moving beyond issues of general research purpose alignment is the issue of scale alignment. As Jones, Fischhoff, \& Lach [21] note, if scientists use models that work on a decade-to-century scale, they may prove to be of no use to policymakers who are concerned with what to do now, 
in the short term. If the time scales of scientific models and predictions do not match up with the time scales decision makers are working from, there becomes a need for more "bridging analysis" that would translate what long-term predictions mean for short-term policymaking. If researchers or intermediaries do not take on this bridging work, the end result is a lack of use of the data in decision-making context [21]. This is critical to think about, as few decision-making organizations are ready or capable of taking the "responsibility for the consequences of their actions decades or centuries in the future or can act at the levels of ecosystems or the Earth system" [11] (p. 61). These issues provide a key opportunity to focus on how to best relay long-term scientific models into short-term decision-making support. Yet even if all of the alignment issues were brought into balance, the incentive and institutional support for researchers to engage in this type of work is often times lacking.

\subsection{Incentives and Training}

There are boundaries within the institution of science itself (disciplines, departments, ideologies, etc.), as well as between science and society [22] (p. 464). Researchers most often times do not have formal institutional incentives to engage in any type of action-oriented research, and may also have to cope with informal "disincentives," like the idea that doing this type of work will be a career choice to forego participation in fundamental research [20]. For many researchers, high value is placed on publishing research in academic journals, with communication of research findings to other audiences not systematically leading to staff appraisal, promotion, or recruitment $[20,23]$. Scholars from many disciplines have noted this clear boundary between basic and "use-inspired" or applied research [23,24]. Whitmer et al. [18] also notes that doing work that involves policymakers or is transdisciplinary in nature often results in multi-authored papers published in interdisciplinary journals instead of "flagship" disciplinary journals, which may result in negative evaluation in terms of promotion or tenure for early-career researchers (p. 317). These formal and informal institutional reward mechanisms impose powerful constraints on the flow of knowledge sharing between researchers and decision-makers [11].

Traditional science and research training also doesn't adequately prepare research professionals to communicate with scientists in other disciplines or outside of the academic sphere. Collaborative policy-centered work requires a high degree of self-evaluation, cultural sensitivity, and adaptability to working with others [25], yet many graduate students and scholars never receive training in these areas. As outlined above, university researchers face several institutional and disciplinary barriers when wanting to engage in this type of work. One suggestion to overcome this issue is to encourage institutional change, or work around the issue by building peer committees that understand the value of both general knowledge advancement and societal action [18]. The Interdisciplinary Tenure and Career Development Committee of the Council of Environmental Deans developed guidelines to help individuals and institutions transition to new standards for engaged work that aims to inform action [24]. Yet this suggestion is ambitious and at times seems unrealistic, as organizations and their underlying structures, cultures, and practices are often resistant and slow to change [11]. It needs to be noted that decision makers don't systematically receive any science training for dealing with pressing scientific or technical issues either, so this particular communication and training deficit appears on both sides of the boundary.

\subsection{Interpretation}

Several studies highlight the key things policymakers need are clear, accessible, and easy-to-understand findings [26,27]. While new science is sometimes needed, the greatest need most often realized is one of translating existing scientific literature and knowledge into a more accessible and usable format [11]. Science communication of this nature involves designing messages that are cognizant and attentive to the social values of audiences [28,29]. Scientists can engage in this work themselves, but often times boundary organizations take on the role of consolidating and translating scientific research. An example of this type of translational work is what is done by the 
Intergovernment Panel on Climate Change (IPCC). The IPCC does not undertake any type of original research, but provides a critical service of reviewing and assessing scientific information that is relevant to understanding climate change [30]. This translational work is key to effective communication, and is something that should be considered as an important step at communicating research findings.

Now that we have outlined several barriers to overcoming the science policy divide, we will address how scholars have proposed changes to address these issues in a more systematic way by turning to the science communication literature.

\section{Discussion}

When considering how to lessen the gap between science and policy, many questions arise: Who should start the conversation and be responsible for maintain the science/policy dialogue? Does it involve one individual or institutions? And how are goals and priorities negotiated? While the literature does not provide clear answers to any of these questions, we discuss two things scientists can consider when trying to advance the impact of their work on policy-making and society.

\subsection{Understand the Power of Context}

Though the barriers we outlined in this manuscript appear as patterns across different science and policy institutions, the importance of understanding how specific energy research is situated in context cannot be overstated. Each energy study has implications for policymakers at different levels, be they local, national, or international; Because of this, it is important for researchers to devote significant time to understanding the current context of their research as it relates to social, economic, and cultural histories. For example, if energy research has policy implications for a small community and researchers are making recommendations for that context in particular, researchers need to tend to the particular communication preferences and dynamics of that group, understanding that they may have different demands and timelines than decision-makers that work in large policy arenas. Smith, Suldovsky, and Lindenfeld [31] documented how communication preferences can vary in legislatures based on term limits, workloads, and partisan history in a specific place. They found that legislators in rural Maine communities preferred interpersonal interaction, whereas other research in different areas shows that legislators prefer white papers or policy briefs [32]. When researchers do background research to better understand policymakers' timelines for decision-making, the processes in which they work, their needs, and what their communication preferences might be, recommendations can be better written for them. In some policy contexts, the idea of reading the policy implications at the end of the academic article might be wholly unfeasible because of shortened timelines for decision-making. In such cases, a policy brief or executive summary can be provided instead. In addition to understanding decision-makers timelines and needs for scientific information, researchers can add use language or "frame" recommendations in ways that will resonate with the decision-makers they are trying to reach.

In Stephens, Rand, and Melnick's [33] content analysis of newspaper coverage of wind energy in three states (Texas, Minnesota, and Massachusetts), they note the power of particular "frames" or narrative structures used to explicate these energy related stories, each which appeal to values of the specific place and culture. They recommend the deliberate use of "frames other than the environmental or climate change mitigation benefits of the technology" [33] (p. 186). They go on to say that the frames used in communicating wind energy should be "responsive to the local and regional context of the place" [33] (p. 186). So when thinking about what terms, "frames", or language to use in crafting policy recommendations, it would be important to understand what is important to the people and in the specific culture of place where the decisionmaking is happening [34,35]. Sovacool [36] emphasises this in work regarding the barriers to renewable energy creation in the United States, noting "despite billions of dollars in research and development ... the impediments to more environmentally sustainable electricity generation remain at least partly social and cultural" 
(p. 372). Technological breakthroughs will never speak for themselves in the embedded cultural context of any society.

The question then is how attend to these aspects of context without allowing the boundary to become too porous, "where personal opinions mix with validated facts, science gets mixed with politics, and the special value of research-based knowledge fails to materialize" [37] (p. 1). It is here that we encourage energy researchers to attend to the human dimensions of communicating research, in an effort to accelerate the impact of their research on decision making and social change. We recognize this might be difficult for researchers who work on highly contentious or political topics within energy studies, which leads us to our second avenue for potential development: using of boundary organizations for assistance with communication when appropriate.

\subsection{Consider the Use of Boundary Organizations and Objects}

Policy literature in the past ten to twenty years has included studies of the role boundary organizations can play in bridging the science and policy divide. Boundary organizations often times provide a rich space for co-production between the two worlds [38]. Boundary organizations are third party institutions that sit between two social worlds, yet have a distinct identity that won't be influenced by the use of either science or policy. This distinction allows for the separation that scientists may look for when communicating with policymakers, especially when dealing with controversial scientific topics. These organizations are often called knowledge brokers, as the aim is to narrow the know-do gap [27], where the "authority of research emerges from the interaction of the research process with the political processes of decision making and change." [22] (p. 459). Boundary organizations can play a key role in these interactions, helping align the research and political processes and manage authority claims of both science and policy. Successful boundary organizations open a bi-directional flow of information between the two areas [39]. Many boundary organizations have distinctive features, including specialized functions within the organization to manage the science-policy boundary, along with transparent and discernable lines of responsibility.

Key to the success of these boundary organizations is the balance of power these organizations provide through accountability. They provide stability to the boundary between science and politics by "being accountable and responsive to opposing, external authorities" [38] (p. 402). Jasanoff [40] sees the role of these organizations as "part of a necessary process of political accommodation among science, society, and the state" (p. 250). An example within energy and climate context would be the IPCC. The IPCC is an intergovernmental body where scientists from member countries across the world contribute to the review and reporting done by the group. The intergovernmental and scientific nature of the group, the IPCC fills a unique opportunity to provide rigorous and balanced scientific information to decision makers [30]. The work of the group is meant to be policy-relevant, helping translate the scientific information produced on climate change around the world into more easily understood formats for use in different decision-making realms. The IPCC is accountable to member governments and the scientists whose work they use. The role of dual accountability allows for deeper negotiations and the pursuit of both scientific and political interest, as it is "tethered to both [science and policy], suspended by the coproduction of mutual interests" [38] (p. 405).

Boundary organizations need buy-in from both sides of the boundary and the credibility of these organizations seems to be a key factor in obtaining that buy-in. Ahmed [10] noted the critical role of people who have standing in both the policy and research communities. These "translators" (p. 767) relay research to policymakers in an understandable format, yet are trusted and capable combating misperceptions or over-simplifications of scientific studies. The presence of these organizations involves both decision-makers and researchers in the research and knowledge production process. Research has shown that this involvement in the process makes decision-makers more inclined to use the resulting findings [41].

Boundary organizations can facilitate various functions depending on the type of policy problem or scenario they are dealing with [42]. For long-term effectiveness and relationship building, boundary 
organizations need stable support that can come from formal institutionalization, network-building, committed funding and personnel [11]. Boundary organizations that serve international constituents, like the IPCC, have received this level of stable support; In contrast, many smaller boundary organizations in local context may find more difficulty in securing stable institutional support for their work. Boundary organizations are only one piece of the puzzle however, and key actors on both sides of the boundary are needed. While recognizing the limitations of boundary organizations themselves, we think it is important avenue to consider for scientific partnership when looking to accelerate energy research impact on policy, particularly as energy research becomes a more political and contentious issue.

\section{Conclusions}

In this manuscript, we reviewed the systematic barriers that often inhibit the flow of information and communication between the science and policy communities. Energy research has a standard of practice where researchers conclude articles with policy recommendations, in essence approaching communication in the vein of the deficit model. While we recognize the challenges in moving away from this model to a more dialogic approach, we argue that moving to a two-way communication model—where attention is paid to context and boundaries—can increase the likelihood of science's impact on policy and society more broadly.

Allcot and Mullainathan [43] in their brief on behavioral science and energy policy write, "What has been missing is a concentrated effort by researchers, policy-makers, and businesses to do the "engineering" work of translating behavioral science insights into scaled interventions" (p. 1205). As this article has suggested, there is no lack of research into energy policy issues; there is however, a significant deficit in the overlap between researchers and policymakers.

To be sure, our suggestions are in no way a comprehensive fix for the barriers between science and policy; however, we consider them an insightful start. Acknowledging the very direct disconnections that happen as a result of the barriers identified here-timelines, purpose of research, and ability to interpret-can be a strong first step to closing the gap. The next step is to understand how communication can help researchers attend to these issues and more effectively engage in dialogue with the policy community. We can do this as a research community by more clearly stating the context of our work in our policy recommendations - even perhaps in the academic articles we write. We can also consider building or strengthening partnership with boundary organizations, who may be more aptly positioned to help move the conversation forward.

Acknowledgments: This research was supported by the National Science Foundation [EPS-0904155].

Author Contributions: Both authors worked collaboratively on the writing of this article.

Conflicts of Interest: The authors declare no conflict of interest.

\section{References}

1. Hoppe, T.; Coenen, F.; van den Berg, M. Illustrating the use of concepts from the discipline of policy studies in energy research: An explorative literature review. Energy Res. Soc. Sci. 2016, 21, 12-32. [CrossRef]

2. Sovacool, B.K. What are we doing here? Analyzing fifteen years of energy scholarship and proposing a social science research agenda. Energy Res. Soc. Sci. 2014, 1, 1-29. [CrossRef]

3. Sovacool, B.K.; Ryan, S.E.; Stern, P.C.; Janda, K.; Rochlin, G.; Spreng, D.; Lutzenhiser, L. Integrating social science in energy research. Energy Res. Soc. Sci. 2015, 6, 95-99. [CrossRef]

4. Stern, P.C.; Sovacool, B.K.; Dietz, T. Towards a science of climate and energy choices. Nat. Clim. Chang. 2016, 6, 547-555. [CrossRef]

5. Suldovsky, B. In science communication, why does the idea of the public deficit always return? Exploring key influences. Public Underst. Sci. 2016, 25, 415-426. [CrossRef] [PubMed]

6. Hansen, J.; Holm, L.; Frewer, L.; Robinson, P.; Sandøe, P. Beyond the knowledge deficit: Recent research into lay and expert attitudes to food risks. Appetite 2003, 41, 111-121. [CrossRef] 
7. Priest, S.H. Misplaced faith: Communication variables as predictors of encouragement for biotechnology development. Sci. Commun. 2001, 23, 97-110. [CrossRef]

8. Smith, H.; Suldovsky, B.; Lindenfeld, L. Mass communication research in sustainability science: Moving toward an engaged approach to address society's sustainability dilemma. Mass Commun. Soc. 2016, 19, 548-565. [CrossRef]

9. Cash, D.W.; Clark, W.C.; Alcock, F.; Dickson, N.M.; Eckley, N.; Guston, D.H.; Mitchell, R.B. Knowledge systems for sustainable development. Proc. Natl. Acad. Sci. USA 2003, 100, 8086-8091. [CrossRef] [PubMed]

10. Ahmed, M. Bridging research and policy. J. Int. Dev. 2005, 17, 765-773. [CrossRef]

11. National Research Council (NRC). Informing Decisions in a Changing Climate; National Academies Press: Washington, DC, USA, 2009.

12. Jasanoff, S.S. Contested boundaries in policy-relevant science. Soc. Stud. Sci. 1987, 17, 195-230. [CrossRef]

13. Ashford, L.S.; Smith, R.R.; De Souza, R.M.; Fikree, F.F.; Yinger, N.V. Creating windows of opportunity for policy change: Incorporating evidence into decentralized planning in Kenya. Bull. Word Health Organ. 2006, 84, 669-672. [CrossRef]

14. Union of Concerned Scientists. Hurricanes and Climate Change. 1 December 2017. Available online: https:/ / www.ucsusa.org/global-warming/science-and-impacts/impacts/hurricanes-and-climate-change. html\#.WmxnNpM-fdQ (accessed on 29 January 2018).

15. Smith, H.M.; Smith, J.W.; Silka, L.; Lindenfeld, L.; Gilbert, C. Media and policy in a complex adaptive system: Insights from wind energy legislation in the United States. Energy Res. Soc. Sci. 2016, 19, 53-60. [CrossRef]

16. Sarewitz, D.; Pielke, R.A., Jr. The neglected heart of science policy: Reconciling supply of and demand for science. Environ. Sci. Policy 2007, 10, 5-16. [CrossRef]

17. Sense About Science (SAS). Peer Review Survey 2009; Sense About Science: London, UK, 2009.

18. Whitmer, A.; Ogden, L.; Lawton, J.; Sturner, P.; Groffman, P.M.; Schneider, L.; Killilea, M. The engaged university: Providing a platform for research that transforms society. Front. Ecol. Environ. 2010, 8, 314-321. [CrossRef]

19. Mulligan, A.; Hall, L.; Raphael, E. Peer review in a changing world: An international study measuring the attitudes of researchers. J. Assoc. Inf. Sci. Technol. 2012, 64, 132-161. [CrossRef]

20. Environmental Research Funders' Forum (ERFF). Using Research to Inform Policy: The Role of Interpretation; ERFF Report 03; ERFF: Swindon, UK, 2007.

21. Jones, S.A.; Fischhoff, B.; Lach, D. Evaluating the science-policy interface for climate change research. Clim. Chang. 1999, 43, 581-599. [CrossRef]

22. Van Kerkhoff, L.; Lebel, L. Linking knowledge and action for sustainable development. Annu. Rev. Environ. Resour. 2006, 31, 445-477. [CrossRef]

23. Cherwitz, R. Viewpoint: The challenge of creating engaged public research universities. Plan. High. Educ. 2010, 38, 61-64.

24. Pfirman, S.; Martin, P.; Berry, L.; Fletcher, M.; Hempel, M.; Southard, R.; Morehouse, B. Interdisciplinary Hiring, Tenure and Promotion: Guidance for Individuals and Institutions; Council of Environmental Deans and Directors: Washington, DC, USA, 2010.

25. Reich, S.M.; Reich, J.A. Cultural competence in interdisciplinary collaborations: A method for respecting diversity in research partnerships. Am. J. Community Psychol. 2006, 38, 51-62. [CrossRef] [PubMed]

26. Colby, D.C.; Quinn, B.C.; Williams, C.H.; Bilheimer, L.T.; Goodell, S. Research glut and information famine: Making research evidence more useful for policymakers. Health Aff. 2008, 27, 1177-1182. [CrossRef] [PubMed]

27. Van Kammen, J.; de Savigny, D.; Sewankambo, N. Using knowledge brokering to promote evidence-based policy-making: The need for support structures. Bull. World Health Organ. 2006, 84, 608-612. [CrossRef] [PubMed]

28. Nisbet, M.C.; Scheufele, D.A. What's next for science communication? Promising directions and lingering distractions. Am. J. Bot. 2009, 96, 1767-1778. [CrossRef] [PubMed]

29. Lindenfeld, L.A.; Hall, D.M.; McGreavy, B.; Silka, L.; Hart, D. Creating a place for environmental communication in sustainability science. Environ. Commun. 2012, 6, 23-43. [CrossRef]

30. Intergovernmental Panel on Climate Change. Organization. Available online: https://www.ipcc.ch/ organization/organization.shtml (accessed on 29 January 2018). 
31. Smith, H.; Suldovsky, B.; Lindenfeld, L. Science \& policy: Scientific expertise and individual participation in boundary management. J. Appl. Commun. Res. 2016, 44, 78-95.

32. Borgenschneider, K.; Corbett, T. Evidence-Based Policymaking: Insights from Policy-Minded Researchers and Research-Minded Policymakers; Taylor \& Francis Group: New York, NY, USA, 2011.

33. Stephens, J.; Rand, G.; Melnick, L. Wind energy in US media: A comparative state-level analysis of a critical climate change mitigation technology. Environ. Commun. 2009, 3, 168-190. [CrossRef]

34. Devine-Wright, P. Beyond NIMBYism: Towards an integrated framework for understanding public perceptions of wind energy. Wind Energy 2005, 8, 125-139. [CrossRef]

35. Wuestenhagen, R.; Wolsink, M.; Buerer, M.J. Social acceptance of renewable energy innovation: An introduction to the concept. Energy Policy 2007, 35, 2683-2691. [CrossRef]

36. Sovacool, B.J. The cultural barriers to renewable energy and energy efficiency in the United States. Technol. Soc. 2009, 31, 365-373. [CrossRef]

37. Clark, W.C.; Tomich, T.P.; van Noordwijk, M.; Guston, D.; Catacutan, D.; Dickson, N.M.; McNie, E. Boundary work for sustainable development: Natural resource management at the Consultative Group on International Agricultural Research (CGIAR). Proc. Natl. Acad. Sci. USA 2011, 113, 4615-4622. [CrossRef] [PubMed]

38. Guston, D.H. Boundary organizations in environmental policy and science: An introduction. Sci. Technol. Hum. Values 2001, 26, 399-409. [CrossRef]

39. Cash, D.W.; Moser, S.C. Linking global and local scales: Designing dynamic assessment and management processes. Glob. Environ. Chang. 2000, 10, 109-120. [CrossRef]

40. Jasanoff, S. The Fifth Branch: Science Advisors as Policymakers; Harvard University Press: Cambridge, MA, USA, 1990.

41. Innes, J.E. Information in communicative planning. J. Am. Plan. Assoc. 1998, 64, 52-63. [CrossRef]

42. Michaels, S. Matching knowledge brokering strategies to environmental policy problems and settings. Environ. Sci. Policy 2009, 12, 994-1011. [CrossRef]

43. Allcot, H.; Mullainathan, S. Behavior and energy policy. Science 2010, 327, 1204-1205. [CrossRef] [PubMed]

(C) 2018 by the authors. Licensee MDPI, Basel, Switzerland. This article is an open access article distributed under the terms and conditions of the Creative Commons Attribution (CC BY) license (http:/ / creativecommons.org/licenses/by/4.0/). 